\title{
A Narrative Game as an Educational Entertainment Resource to Teach Words to Children with Learning Deficits: A Feasibility Study
}

Marcos Alexandre Rose Silva ${ }^{1}$, Débora Corrêa de Lima ${ }^{2}$, Junia Coutinho Anacleto ${ }^{3}$, Deisy das Graças de Souza ${ }^{4}$, and Claudia Maria Simões Martinez ${ }^{5}$

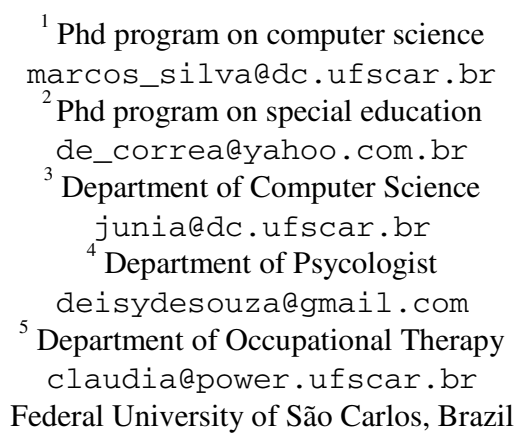

\begin{abstract}
We describe the use of an entertainment computer narrative game to teach words to a child in a special education process. In order to observe the potential of this kind of game, we chosen a child who has difficult to learn some words using a basic computer tool at writing learning special education environment. The results showed that narrative games and its entertainment resources can be a good way to allow child reads and writes words considering different sentences and contexts, as well as, resources of the game can be a useful strategy to engage child on the storytelling.
\end{abstract}

Keywords: Narrative game, writing, special education.

\section{Introduction}

Computer games can be useful educational tools because they are fun, as well as, they motivate students, support learning and increase students' learning capacity [8]. This kind of game supports students to improve their mental and intellectual skills, once it encourages students to participate in a more enjoyable, fun and productive class [2]. Piaget [4] discusses that games are directly related to the children's development.

Games can be classified as [7]: recreational, cooperative, educational and narrative. Narrative games use storytelling which people participate within the game story, telling facts, events and story details in a collaborative and attentive manner [3]. An example is a game called RPG Role Playing Game where people need to create a story together.

In RPG, there are participants and the master, who usually is the most experienced player and his/her task is to present the story to the participants, with characters, their characteristics, scenarios [7]. 
In this context, this paper presents feasibility study done by four different disciplines, which are computer science, special education, occupational therapy and psychology, from the Federal University of São Carlos (UFSCar) in Brazil, related to the use of a narrative game computer game to support a child at writing learning special education environment.

The feasibility study goal was to observe the narrative game potential to teach some words to a child who has learning deficits. For this propose, a narrative game with RPG characteristics was chosen because an educator as master can create a story considering child's knowledge, characteristics, likes and learning deficits. Child as participant can practice and learn how to write some words during the story.

This feasibility study focused on observing and documenting (1) how child uses a narrative game, and (2) the effects of entertainment storytelling in language learning in order to observe if it can help a child, who had difficulty to learn some words through a current tool, used in special education environment at UFSCar, called Read and Write through Little Steps (LRWLS).

\subsection{Read and Write through Little Steps (LRWLS)}

LRWLS [5] uses the "stimulus equivalence theory". In this theory, reading and writing skill can be taught through stimulus using wrote words, spoken words, pictures which students need to relate to each other [6]. There are many types of lessons in LRWLS, such as: hear a word and type it, hear a word and click on figure which represents it, etc. Through these lessons, it is possible to identify what kinds of writing or reading deficits students have because considering students game interaction, this tool can show a report about what words were not typed correctly; what are correct words and how students typed it, etc.

Therefore, educational professionals, using this tool, can identify students who do not know how to write or read specific words. For example, words which contain the letter pairs $\mathrm{NH}, \mathrm{RR}, \mathrm{CH}, \mathrm{SS}$. Educational professionals have noticed that this tool is a good way to teach words [5] yet some students have difficulty on learning some words. Because of that, we decided to perform a feasibly study to investigate the use of a narrative games to teach words taking into consideration story context in order to help children learn while they are playing and having a good time.

\subsection{Narrative Game}

There are some narrative games in Brazil [1], of which we have chosen one called Contexteller because it allows the creation of stories with any scenarios and characters. We wanted to have the possibility of creating a story according to students' knowledge, characteristics, likes and learning deficits. Other narrative games [7] only support games with fixed sets of characters, characteristics, scenarios and themes. Contexteller was also developed by the Computer Department at UFSCar, making it easier to modify.

Contexteller is a narrative game inspired in Role-Playing Games - RPG [7]. Fig. 1 shows the interface of the game, allowing the players (mater and participants) to see their card (I) with a specific text area where players can type their messages, their dice (II), and (III) another text area which allows players to read all the messages sent to each other during the composition of the collaborative story. In area (IV), the card, with another color and size, represents the master of the game, and area (V) shows to other characters' card. 


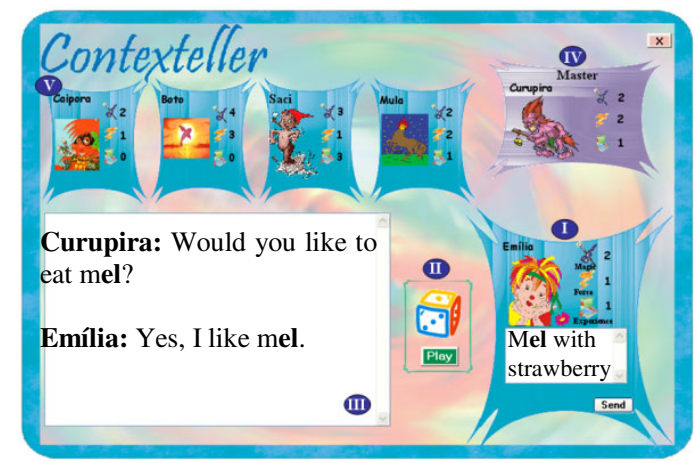

Fig. 1. Interface of Contexteller

The dice (II), which is also part of the RPG, shows the players whether a particular action is possible, or not [7]. For example, to raise any object it is necessary to have the value of the Force element equal or greater than the value of the object weight. This weight is defined by value of the dice thrown by the player. Thus, the player can raise the object if the value of the Force is equal to $\mathrm{N}$ and the value of the dice is from 1 to $\mathrm{N}$. If the value of the dice exceeds $\mathrm{N}$ such action will not be possible because the value of the weight of the object is more than the value of the Force element.

\section{Feasibly Study}

There were 2 steps in the feasibly study: (1) showing narrative game to child in order observe how s/he uses a game (2) teaching words through narrative game considering his/her deficits.

Participant - It was used the reports from LRWLS tool in order to identify a child who had difficulties to learn some words using this tool, that is, a child that did not write correctly in the lessons. Our subject was an 11 years old girl that did not write correctly words which contain any vowel followed by the letter 1 . For instance, caldo, mel, multa, etc (in English juice, honey, fine, etc). It is important to say that we chosen just one child because we think that it is important to know more about a different activity before doing it with a lot of children. Objective - To observe if a specific narrative game can help child to learn some words, such as caldo, mel, multa (in English juice, honey, fine). Hypothesis - Storytelling can allow child to see specific words in a story, created for this propose, and then write them. This process can help her to learn in this sequence: seeing words when Maters types them; seeing words to copy them in a story; using words in different sentences and moments of the story. Method - Researchers created a story considering child's knowledge, characteristics, likes and taking into consideration these words. Because of that, the context of the story was defined in order to allow the use of them. 


\subsection{First Step}

We talked to the child about what she liked watching on tv, movie, etc, in order to collect information that would help us create a story which she could identify with. This information was used to create a story for Step 2 which we intended to teach words. In this step, the objective was to show a narrative game to her in order to observe how she uses it. It is important to say that during both Step 1 and 2, there were two researchers with child, one to tell the story with child and another one to note observations and to help her. Table 1 shows part of story that we told with her.

Table 1. Part of the first story

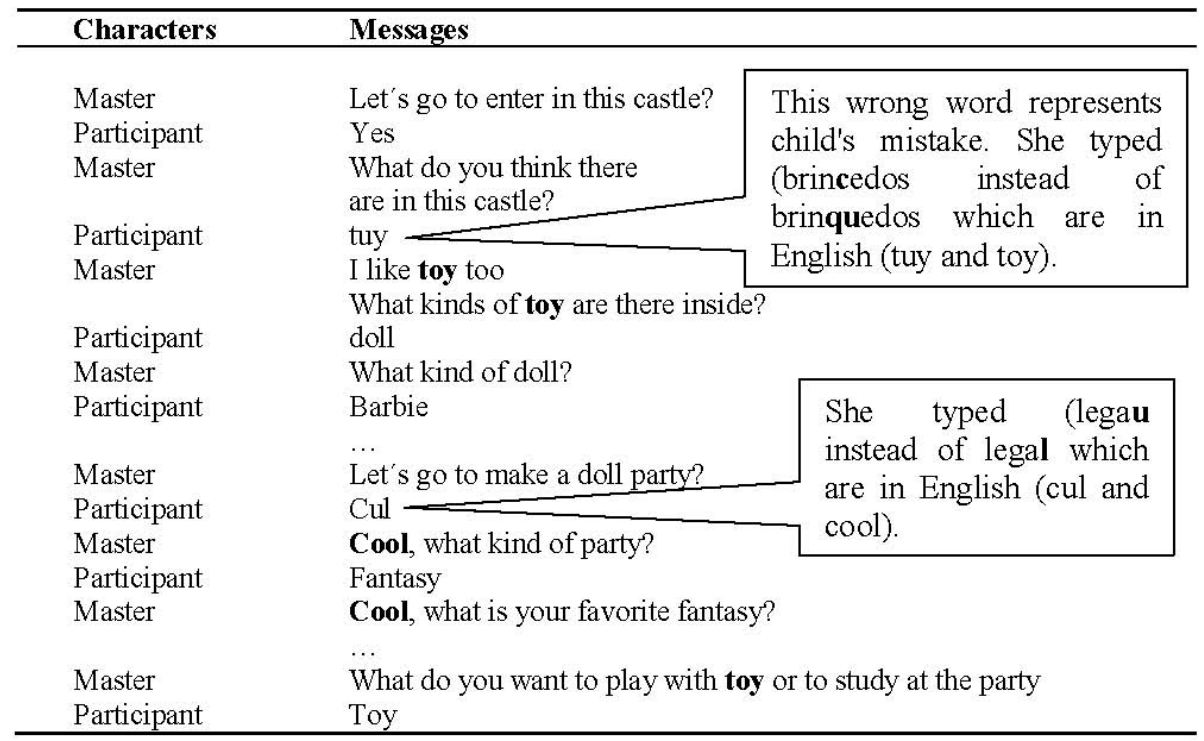

Through this story, we could start observing the potential of storytelling to support child on learning process. For example, when child typed "tuy", we started writing this word in a correct way "toy" in order to help her to observe the mistake. It is important to say that we did not say anything about this mistake to her during the story because this correction process could discourage her to tell story. Nevertheless, she wrote the word correctly after. We can't say that she learned the word yet she had a possibility to see and type this word many times.

Other interesting information was about the word "cool" because child wrote "cul" and immediately we used the same strategy described above, i.e., repeating this word during the story. In this case, the child said "oh cool has double 'o', no ' $u$ ' (showing cool which master typed)". Then, we noticed that child can notice a mistake during a story without master says "you are wrong or this word is not correct".

We also noticed that she did not pay a lot of attention in the story because most of the time she spoke a lot and wrote short sentences. In contrast, in her little moment of attention was useful to notice a mistake and to write a word correctly. 
We decided to make another session in this Step 1 without teaching specific words because we wanted to understand more about the potential of narrative game before using it to teach some words. We continued with the same context story. In this session, we noticed that story is a way to observe if children learned a word. For example, child already learned some words like chess and piece but she did not type them correctly during story. According reports from LRWLS tool she had a good performance with these words yet she did not know how to write them during story.

Considering narrative game options, we started using dice in this story. She liked to see the movement of the dice a lot and after seeing a number on it. There is an animation which moves the dice when Master releases it and this animation also shows a number between 1 to 6 when child clicks on it.

Using the dice, it was possible to observe how entertainment options can help child's interest and engagement because she paid more attention in this story to know exactly when she could use it. In contrast, we noticed that she did not understand the dice goal considering RPG role. She liked playing the dice to compare its value with Master's dice value because both of them played the dice at the same time, in this story. After this comparison, she checked who had the higher dice value and asked to play again. We played the dice three times and she laughed a lot. Then, we continued with the story and sometimes the Master released the dice.

\subsection{Second Step}

In this step, we started teaching words through narrative game considering her likes and deficits. , i.e., we created a story considering what she liked to watch on tv, movies, etc., and some words that she did not know how to write, such as: caldo, mel, multa (in English juice, honey, fine).

Our goal was to teach two words during the story which are mel and caldo. Firstly the Master tried to teach the word mel but she did not write it. After, four attempts Master tried to teach another word in order to change the story a little beat. Nevertheless, she also did not write caldo. Through this experience, we noticed that it is very difficult to try to teach two words in the same story. Then, we decided to teach only one in each story.

In another session, we decided to talk to child about the story in order to explain that the story was related to mel (honey), then, we could play the dice if someone wrote this word. The master decided to show her that she typed the word correctly saying "good" and releasing the dice. It was curious because she played the dice and she wrote after "I want to play the dice again". Master wrote "ok, but you need to write what you like to eat with mel before", and she wrote another sentence with mel.

In order to observe child learning process, we continued with the story about mel in another session. We wanted to observe if child could write the word correctly in different sessions. The story was about dessert which contains mel. When child wrote desserts which contain mel, she played the dice. In this story, she had a good participation. Because of that, Master and she could write about the taste of mel and who animal does it. 


\section{Discussion}

This paper presents a discussion about the use of a narrative game to support children from special education to learn words. We noticed that this kind of game can be useful to support children to repeat the same word in different sentences and contexts. In contrast, it is not easy to ask a child to repeat a word during the story. The Master needs to be precise about what they want in her/his writing. For example, it is not good to write "What food do you like to eat with honey?". It is better to write "we are going to tell a story considering the word honey" in the beginning of the game. This way can help children to understand what they need to write in the story. We also noticed that story is a way to observe if children learned a word. For example, some words that child already learned such as: xadrez and peça (in English, chess and piece), she did not type them correctly during story.

It is very important to say about the necessity of entertainment resource in order to stimuli the child during the story. Our case was the dice, it was a useful and fun strategy to encourage child to write the word mel. In contrast, it is important to design simple entertainment resources. In our context, to teach words to child with learning deficits, we needed to keep the focus on teaching words instead of to teach entertainment resources from narrative game. We could not spend much time on teaching game resources because our objective was to teach words. Because of that, the game and its resources need to be easily and friendly in order to support children to learn how to write and, its resources cannot be a challenge where children also need to learn about.

Acknowledgments. We thank CAPES and FAPESP (2010/52135-9) for partial financial support to this research.

\section{References}

1. Bittencourt, J.R., Giraffa, L.M.: Role-Playing Game, Educação e Jogos Computadorizados na Cibercultura. In: I Simpósio de RPG em Educação, p. 14 (2003)

2. Marcatto, A.: Saindo do Quadro, p. 189. Alfeu Marcatto, São Paulo (1996)

3. Oaklander, V.: Windows to Our Children: A Gestalt Therapy Approach to Children and Adolescents, p. 335. Gestalt Journal Press (1988)

4. Piaget, J.: Judgement and Reasoning in the Child, p. 268. Littlefield Adams, Richmond (1999); Smith, T.F., Waterman, M.S.: Identification of Common Molecular Subsequences. J. Mol. Biol. 147, 195-197 (1981)

5. Rosa Filho, A.B., et al.: Aprendendo a ler e a escrever em pequenos passos. Software Para Pesquisa (1998)

6. Sidman, M.: Equivalence relations and Behavior: A research story, p. 475. Authors Cooperative, Boston (1994)

7. Silva, M.A.R., Dias, A.L., Anacleto, J.C.: Processing common sense knowledge to develop contextualized computer applications. In: García-Pedrajas, N., Herrera, F., Fyfe, C., Benítez, J.M., Ali, M. (eds.) IEA/AIE 2010. LNCS, vol. 6096, pp. 215-224. Springer, Heidelberg (2010)

8. Tarouco, L.M.R., Roland, L.C., Fabre, M.J.M., Konrath, M.L.P.: Jogos educacionais. In: CINTED - Centro Interdisciplinar de Novas Tecnologias na Educação (2004), http: / / www. ueb-df.org.br/Adultos/Reflexoes / Jogos\%20Educacioanis.pdf (November 2007) 